\title{
Where mitigation and migration meet
}

\author{
Climate migration involves complex interactions of environmental, social, political and economic factors. \\ New research suggests that although wealthy global citizens try to prevent climate migration, they are willing \\ to shoulder a greater share of the climate mitigation burden when extreme climate events hit poor countries.
}

\section{Reuben Kline}

\section{S} ome forecasts predict that increasing climate disruptions will create up to 200 million or more climate migrants by 2050 (ref. ${ }^{1}$ ). This mass movement will have profound implications for global immigration and climate politics. Less economically developed regions are more vulnerable to the negative effects of climate change, and this vulnerability is a driving factor in climate migration ${ }^{2}$. Faced with an influx of climate migrants, citizens of the would-be destination countries, although richer, less vulnerable and more responsible for climate change, could attempt to restrict climate migration to protect their own interests. At the same time, if we wish to avoid the most catastrophic effects of climate change, including even greater mass migration, the task of mitigation through collective efforts will be imperative.

Because economic development, immigration and climate change are inextricably linked and intertwined with many other factors, it is a difficult context in which to identify causal mechanisms. Doing so is important because a better understanding of the behavioural factors that drive climate migration can help improve integrated assessment modelling and inform policy responses. In this context, relying on observational data can be problematic because of the multiple interdependent factors. Writing in Nature Climate Change, Jochem Marotzke and colleagues $^{3}$ use a series of incentivized experimental economic studies with real monetary stakes to highlight the key strategic features of the problem and begin to answer questions about the migratory responses to climate shocks and to what extent they are distinct from purely economic drivers of migration. Based on careful control over the material incentives and strategic environment, these experiments offer the ability to robustly identify causal mechanisms and address these crucial questions.

In particular, Marotzke et al. introduce a novel variant of the collective risk social dilemma, a threshold public goods game that simulates the prevention of economically disastrous climate change ${ }^{4-6}$. Players in small groups are endowed with operating funds, some portion of which can be contributed - over multiple periods - toward a target threshold. If the group's collective contributions meet or exceed this threshold, the group avoids a collective loss of earnings and each member retains whatever they did not contribute. If the group's collective contributions fall below the threshold, players face a collective risk - a probability that they lose all their remaining funds. As in all public goods games, there is an incentive to free ride - in this case, disaster prevention is the public good and free riding entails letting the other player pay to stop the disaster while benefiting from their prudence.

Marotzke et al. add a few twists to this classic paradigm. They vary the amount of funds participants are given to begin the game by creating two 'countries', one inhabited by wealthy participants and one by poor participants. Each country has harvests, but in the rich country, not only are the players twice as wealthy to begin with, their harvests are twice as valuable. During the game, players can migrate from one country to another. This baseline condition isolates the effect of pure economic migration. An additional condition adds the potential for the poor country's harvest to be impacted by climate shocks that, if they occur, wipe out the poorer country's harvest for three rounds of play. This feature provides further incentive for the poor country's inhabitants to migrate and distinguishes climate migration from the purely economic migration observed in the baseline condition.

The results show that climate disruptions increase intentions to migrate by the impoverished. Wealthy participants, however, can attempt to block immigration. They may want to do so because immigration would mean they have to divide the same harvest among more people. This makes restrictions beneficial to the rich country's inhabitants overall, but in the experimental setup, four out of five wealthy participants must be willing to pay a cost in order to block immigration. This makes restricting immigration a collective action problem in its own right. So, although individual rich players do frequently attempt to block immigration, these attempts are typically unsuccessful. When poor countries are hit by climate shocks, rich players attempt to block migration from poor countries while at the same time voluntarily increase their own contributions toward the mitigation threshold. These results demonstrate that under controlled conditions, mitigation behaviour (contributions toward the threshold) and migration dynamics are interdependent.

The results of Marotzke et al. show that climate shocks to poor, vulnerable populations cause wealthier and less vulnerable populations to increase their share of the mitigation burden. This suggests two potential motivations for doing so, neither of which need to rely on altruism from the wealthy. First, because contributions toward the threshold reduce the risk of climate disaster, contributions potentially benefit all players, including the contributor themself. Wealthy players, if only to avoid losing their own funds, might therefore want to make up for the reduced means to contribute by the now even poorer players. This is consistent with other research that shows the wealthy increase their mitigation efforts because they have more wealth to lose $\mathrm{e}^{7}$. Second, the wealthy players could increase their contributions in order to forestall immigration. If the poor can safely contribute less because of increased contributions from the wealthy, they keep more money in their own pockets, reducing their incentive to migrate toward greener pastures. Nonetheless, poorer people are not only impoverished but are the most vulnerable to and the least responsible for the negative effects of climate change $e^{8,9}$. Actively blocking one of the few options they have to improve their plight is thus likely to be ethically controversial, but Marotzke et al.'s 
results raise the possibility of increased mitigation efforts by the wealthy as a countervailing (consequentialist) ethical consideration. The study illuminates distinct yet interdependent motivations underlying climate migration and highlights the fraught ethical issues at stake when considering immigration in the context of climate change. In doing so, they provide a useful guide for future research on the ethics and political economy of climate change and migration.

The COVID-19 pandemic and its global economic consequences will likely create economic devastation in developing countries, leading to pressure for emigration from countries hardest hit. At the same time, the economic strain will be high on potential destination countries, likely creating a call for immigration restrictions. Climate change will still continue largely unabated, increasing the chances of mass climate migration. Marotzke et al. ${ }^{3}$ demonstrate that rigorous behavioural science work can provide useful insights into the complex interactions between ethical, political and economic issues that can be used to inform future climate policy.

\section{Reuben Kline (D) $ه$}

Department of Political Science and Center for Behavioural Political Economy, Stony Brook

University, Stony Brook, NY, USA.

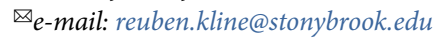

Published online: 25 May 2020

https://doi.org/10.1038/s41558-020-0796-y

References

1. Kamal, B. Climate migrants might reach one billion by 2050 . Inter Press Service News Agency http://www.ipsnews.net/2017/08/ climate-migrants-might-reach-one-billion-by-2050/ (2017).

2. McLeman, R. A. \& Hunter, L. M. Wiley Interdiscip. Rev. Clim. Change 1, 450-461 (2010).

3. Marotzke, J., Semmann, D. \& Milinski, M. Nat. Clim. Change https://doi.org/10.1038/s41558-020-0783-3 (2020).

4. Milinski, M., Sommerfeld, R. D., Krambeck, H. J., Reed, F. A. \& Marotzke, J. Proc. Natl Acad. Sci. USA 105, 2291-2294 (2008).

5. Tavoni, A., Dannenberg, A., Kallis, G. \& Löschel, A. Proc. Natl Acad. Sci. USA 108, 11825-11829 (2011).

6. Jacquet, J. et al. Nat. Clim. Change 3, 1025-1028 (2013).

7. Del Ponte, A., Delton, A. W., Kline, R. \& Seltzer, N. J. Politics 79, 1444-1448 (2017)

8. Kline, R., Seltzer, N., Lukinova, E. \& Bynum, A. Nat. Hum. Behav. 2, 653-661 (2018).

9. Füssel, H. M. in Climate Change, Justice and Sustainability (eds Edenhofer, O. et al.) 9-17 (Springer, 2012).

\title{
Warming shrivels future snowstorms
}

\author{
The influence of the changing climate on individual snowstorms has been uncertain, in part due to the use of \\ coarse model simulations. Now, research employing more detailed simulations finds fewer and smaller snowstorms \\ as a result of warming, with a reduction in the amount and extent of extreme snowfall.
}

\section{Martin A. Baxter}

$\mathrm{F}$ rom ski resorts to farms to roadways, much of North America's population is substantially impacted by snowstorms (Fig. 1). Accurate depictions of future climate rely on correct representation of snowstorms, as these events influence other physical climate processes. Thus, realistic estimates of changes in snowstorms are highly desirable. Writing in Nature Climate Change, Walker Ashley, Alex Haberlie and Vittorio Gensini ${ }^{1}$ analyse simulations of future North American snowstorms on a scale capable of resolving the high-impact aspects of the storms, such as intense bands of snow. Their analysis provides the most detailed estimates of US snowfall changes to date, which will prove useful in the development of plans to mitigate and adapt to future climate.

Water from snow, snow cover extent and maximum seasonal snow depth have all decreased over North America since $1960\left(\right.$ ref. $\left.^{2}\right)$. While a warmer climate is associated with both increased evaporation and a capacity for more water vapour in the atmosphere, accumulating snowfall can only occur when surface temperatures are below freezing. General circulation model (GCM)-based studies expect a greater proportion of total cold-season precipitation to fall as rain $^{3}$, reducing midlatitude snowfall ${ }^{4}$. Warmer temperatures will also reduce snow season length ${ }^{3}$. One of the challenges of estimating the influence of climate change on snowstorms lies in the fact that some regions have the potential to experience increased snowfall, as enhanced atmospheric water vapour is transported to regions cold enough for snow, even in the presence of increased global temperatures ${ }^{5}$.

Ashley and co-authors ${ }^{1}$ analyse hourly output from simulations performed using the Weather Research and Forecasting model on a $4-\mathrm{km}$ grid, as described in ref. ${ }^{6}$. The data consist of two 12-year simulations, one of recent climate (2000-2013) and another of future climate (representing the final decades of the twenty-first century). Historical climate simulations were driven using initial and boundary conditions from the ERA-Interim reanalysis ${ }^{7}$, a gridded data set representing historical weather at a spatial resolution of about $80 \mathrm{~km}$. To simulate future climate, these experiments used ERA-Interim boundary conditions with future (2071-2100) climate anomalies added from the ensemble mean of the Coupled Model Intercomparison Project Phase 5 high-end emissions scenario. This experimental setup, often referred to as a 'pseudo-global warming' (PGW) approach, is commonly employed in regional climate studies to investigate a variety of phenomena ${ }^{8}$.

Statistically significant changes in a variety of meaningful snowstorm characteristics are observed by Ashley and co-authors ${ }^{1}$. The PGW scenario exhibits nearly $28 \%$ fewer snowstorms per year. The year with the fewest snowstorms in the recent climate is equivalent to the year with the highest number of snowstorms in the PGW scenario. The average snowstorm size decreased by $37 \%$, equivalent to an area roughly the size of the US Great Lakes. Fewer and smaller snowstorms result in an average 33\% decrease in total annual frozen precipitation. The areal extent of 